\title{
A deeper shade of green
}

\section{Stephen Cotgrove}

The Global Environmental Movement. By John McCormick. Belhaven Press: 1989. Pp. 259. £22.50, \$35. Distributed in the United States by Indiana University Press.

IN 1661, the naturalist John Evelyn was deploring the air pollution from coal burning which made the City of London resemble "the Court of Vulcan... or the Suburbs of Hell". But man-made environmental disaster was by no means a new phenomenon, even then. The abandonment of Sumerian cities nearly 3,700 years ago, overgrazing and deforestation resulting in the soil erosion of the hills of Attica, and the collapse of Mayan civilization through over-population, are but a few early examples.

By the second half of the nineteenth century, rising concern had spawned several protectionist groups. In Britain, the Society for the Protection of Animals was founded in 1824. The impact of industrialization on towns and countryside led to a growing criticism of its challenge to the moral and social order. The National Trust and the Council for the Protection of Rural England are but two monuments to growing public concern. In the United States, anxiety focused on the preservation of the wilderness and the great national parks, with the founding of the Sierra Club in 1892 . By contrast, and to some extent in conflict with these ideals, the conservationist movement sought to promote the sustainable and 'rational' exploitation of natural resources.

The Global Environmental Movement documents the unfolding story of the gradual growth in environmental consciousness and concern until it reaches global proportions with the emergence of international agencies and cooperation after the Stockholm Conference of 1970-72. McCormick's book is scholarly and well researched, as is to be expected from a text which has its origins in a postgraduate dissertation. But McCormick's strength is also his weakness: he is long on description and short on analysis.

In Britian, three million people are now members of environment groups, "making the movement the biggest in British history" (p. viii). McCormick recognizes that this 'movement' is of great complexity. There is little in common between members of the National Trust and Greenpeace save a concern for some aspect of the environment. To describe all these groups as members of the same movement is to underplay the deep differences in goals and values, in perceptions of what constitute threats to the environment, and in what are considered to be the appropriate strategies of environmental protection.
Although McCormick acknowledges such complexities, the issues raised are barely addressed and certainly not treated in any depth. The absolutely crucial distinction is between 'deep' and 'shallow' ecology (or deep and pale greens). These two poles of the 'movement' differ dramatically both in their perceptions of the \section{늘}

\section{IMAGE UNAVAILABLE FOR COPYRIGHT REASONS}

United, but for how long? Environmental groups demonstrating against nuclear weapons.

threats facing the environment, and in their prescriptions for cure. To take one example - the exponential growth in human numbers compared with the arithmetical increase in food supply, first noted by William Petty and subsequently popularized by Thomas Malthus 150 years later. It was not until 1972 that the publication of two influential books again raised the spectre of disaster. To the threat of catastrophe from the population explosion, the Blueprint for Survival and the Club of Rome's Limits to Growth added dire warnings that exponential economic growth was unsustainable. Such views were heavily criticized and even ridiculed by the scientific and political establishment at the time. The Doomsday
Syndrome by John Maddox, for example, was a powerful and authoritative critique. Other critics were less temperate epithets such as "eco-hysteria", "ecomaniacs" and "eco-nuts" were hurled at the "doomsters".

All of this is faithfully recorded by McCormick. What is a little disappointing is that he stops short of coming to grips with the problems and issues raised by such varied responses to environmental threats. Why are there such dramatic differences in perceptions of environmental dangers and in prescriptions for action? In his final chapter, McCormick begins to outline an explanation, but sketches it in only lightly and briefly. He notes the assertion that the roots of an environmental crisis are to be found in the dominant culture of industrial society - a coherent ideology which includes faith in science and technology, the subjection of nature and its exploitation as a resource, and, above all, a deep commitment to economic growth by government. Those (the great majority) who see the world from this perspective are markedly less likely to perceive environmental dangers, and markedly more likely to believe that market forces and science and technology will provide solutions.

McCormick is optimistic that a fundamental change in attitudes is under way. But no amount of concern over litter and waste disposal, driving fuel-efficient cars and conserving energy will address the challenge raised by the deep greens - the possible exhaustion of the world's stock of mineral resources in a tiny fraction of the duration of man's life on Earth, and the doubling of the world's population in the next 30 years. Above all, the pressures for continuing economic growth on which democracies depend for their stability, and the aspirations of the developing world, may well be inexorable.

The attitudes, beliefs and values which constitute the dominant culture of industrial societies are deeply rooted in upbringing, experience and interests. To see the world as the deep greens see it requires something akin to a religious conversion. It is such unproven and largely untestable assumptions that structure the way we 'see' the world and interpret the evidence. Above all, values are not testable in the laboratory. And what is reasonable and rational action to maximize one value protecting nature - may seem irrational to those for whom economic values are self-evident benchmarks. It could be that it is the world view of the deep greens which is 'realistic'. But it may take a crisis to challenge the dominant industrial culture, with its bias against the environment. By then, it may be too late to prevent irreversible damage.

Stephen Cotgrove is Emeritus Professor of Sociology at the University of Bath, Caverton Down, Bath BA2 TAY, UK. 